\title{
Assessment of the role of school health nurses/school health supervisors in the prevention and control of communicable diseases in primary schools in Derna, Libya
}

\author{
Saria M. Arhaim, Raga A. Elzahaf* \\ Department of Public Health, Faculty of Medical Technology, Derna, Libya \\ Received: 17 August 2016 \\ Accepted: 10 September 2016 \\ *Correspondence: \\ Dr. Raga A. Elzahaf, \\ E-mail: raga_128@yahoo.com \\ Copyright: ( ) the author(s), publisher and licensee Medip Academy. This is an open-access article distributed under \\ the terms of the Creative Commons Attribution Non-Commercial License, which permits unrestricted non-commercial \\ use, distribution, and reproduction in any medium, provided the original work is properly cited.
}

\begin{abstract}
Background: The nurse's role is primarily a manager of the health services program, she provide the leadership or play a supporting role in prevention and control of communicable diseases in schools. She is the first point of contact in the school on most health services. The aim of the present work was to assess of the role of the school health nurse/ school health supervisor in the prevention and control of communicable diseases in primary schools in Derna, Libya. Methods: A cross-sectional study design was used. The study was conducted in the primary schools of Derna city, Libya. The study included all nurses (50 nurses) working in 26 primary schools. Data was collected used a predesigned and structured questionnaire to collect the personal characteristics and specially constructed observational checklist was prepared to assess the role of SHNs/SHSs regarding prevention and control of communicable diseases.

Results: About two thirds of the studied sample aged 30 to <40 years $(62.0 \%)$. Majority of them $(96.0 \%)$ were responsible for one school, with workload of 200 to $>410$ students. About three quarters of them received training courses in school health. $58.0 \%$ of the studied sample adequately performed their activities regarding prevention and control of communicable diseases.

Conclusions: The study recommends increase awareness of school principals on the school-nursing role, especially in issues related to prevention and control of communicable diseases.
\end{abstract}

Keywords: Assessment, School health nurses, School health supervisors, Prevention, Control of communicable diseases, Primary schools

\section{INTRODUCTION}

Children are the greatest investment of any community and the main basis for its development. They are the biggest promise for the future. Since they are the parents, workers, leaders, and decision-maker of tomorrow. The nation's destiny lies with the health, well-being and safety of its children because healthy children are vital resources to ensure the future and well-being of a nation. ${ }^{1-3}$ School children needed to be provided with appropriate knowledge and life skills in order to enable them to make healthy decisions and choices, to adopt a healthy lifestyle and to deal with conflicts. ${ }^{4}$

School nurses have responded to changes in school health by assuming a wide variety of roles. ${ }^{5}$ They are important members in the health team of the school. They provide services at school, with the families of the children, and in the community. School nurses are not just bandage dispensers, first aid providers, and record keeper. The nurse's skills and training prepare for broader roles as 
health counsellors, facilitators, and educators within the school and community. ${ }^{6}$

However, communicable diseases are one of the most common causes of student absenteeism. Communicable disease - An infectious or contagious disease that can be transmitted from one person to another by direct physical contact, infected airborne droplets. ${ }^{7}$ Prevention and control of communicable diseases are recognized as essential responsibilities of the school nurses. ${ }^{8}$

It is important to realize that methods used to control the spread of communicable diseases in the school setting have limitations. Many diseases have periods of communicability that precede the onset of identifiable symptoms or are without symptoms throughout the entire contagious period. Consequently, efforts to prevent or control the spread of communicable diseases must continue on an on-going basis. ${ }^{8}$

The nurse's responsibility in communicable disease control is to determine student at risk, students with close contact, students or staff in the same classroom, and family members, determine who will provide the required intervention, develop strategy for early identification of additional cases, an exclusion policy. ${ }^{9}$ Also she should be knowledgeable about current communicable disease regulations and control, current reportable diseases, collaborate with health care providers on limitations for the child upon return to school, promote prevention and control through health education, staff in-services and by serving as a resource person to staff, provide health counselling to parents and guardians regarding appropriate treatment and follow-up. The school nurse has to refer to medical provider when indicated, notify school administrators in the event of a communicable disease outbreak and follow guidelines established, document appropriate information in the student's record, and develop and write policies and procedures in collaboration with school administration. ${ }^{7}$

Little is found in the literature related to the evaluation of the role of school nurse in the implementation of the school health services in Libya. Therefore, the aim of the present work is to assess the role of school health nurse /school health supervisor (SHNs/SHSs) in the prevention and control of communicable diseases in primary schools in Derna, Libya.

\section{METHODS}

A cross-sectional study design was used. The study was conducted in the primary schools in Derna city, Libya from January to March 2015. The study included all 50 nurses working in 26 primary schools.

The part of prevention and control of communicable diseases in a specially designed observation checklist based on the WHO/MOHP tool developed in compliance with the WHO/MOHP guideline for services provided to school children through school health clinics was used to assess the role of SHNs/SHSs which included; the

students are checked during class visits for communicable diseases, early detection of communicable diseases, care for contact, back to school after communicable diseases, role of the nurse regarding the absent students and vaccinations. ${ }^{4}$ And the predesigned and structured interview questionnaire was used to collect the personal characteristics of SHNs/SHSs including age, marital status, whether she had children or not, qualifications, years of experience in school health, number of schools and students which the nurse is responsible for, and type and number of training courses related to school health.

Each nurse/supervisor was shadowed for three days during her working hours whether in clinic, classroom or other areas of the school by first investigator. Items of practices that were not performed during observation period were inquired about by asking the school nurse.

\section{Statistical analysis}

Data analysis was performed using SPSS software version 20. Descriptive statistics, including percentage, mean, range, and standard deviations, were calculated for all variables. Proportions were compared using Chisquare tests and $P$-value less than 0.05 was considered statistically significant. The role of SHNs/SHSs regards the prevention and control of communicable diseases aspects of school health program were classified into 6 major items.

Each item considered of a number could be formed of number of items. Each item given score 1(performed) or 0 (not performed). Mean score percentage for each item was obtained as following:

- The total score for each item was obtained by multiplying the number of times the item was performed by 1 .

- The maximum score for each item was obtained by multiplying total number of entries by 1 .

- The total score was divided by the maximum score for each item. Resulting figures multiplied by 100 to convert score into score percentage.

Then score percentage was transferred into categories as follows.

- Inadequate score: for those who have score $\%$ $<60.0 \%$

- Adequate score: for those who had a score \% $\geq 60.0 \%$.

\section{RESULTS}

The mean age of the study sample of SHNs/SHSs was $35.9 \pm 6.5$ years with about two thirds of them were within 
age group of 30 to less than 40 years $(62.0 \%)$, while $14.0 \%$ of them were less than 30 years. Most of the study sample $(78.0 \%)$ was married, and $88.1 \%$ of them had children. Only half of nurses $(50.0 \%)$ have a bachelor degree in other have health related field certificate and only $10.0 \%$ of them were graduated from the college of nursing. However, most of nurses (96.0\%) were responsible for one school. And $66.0 \%$ of study sample had from 200 to less than 300 children in their responsibility, while $16.0 \%$ of them had from 300 to 410 children in their responsibility. Furthermore, $42.0 \%$ of the study sample had experience of less than 5 years and only $4.0 \%$ of them recorded 15 to 23 years of experience with mean years of experience was $2.0 \pm 0.9$ years.

Table 1: Distribution of the studied sample of SHNS/SHSS working in primary schools by some characteristics.

\begin{tabular}{|c|c|c|}
\hline Personal characteristics & $\begin{array}{l}\text { Number } \\
(n=50)\end{array}$ & $\%$ \\
\hline \multicolumn{3}{|l|}{ Age(year) } \\
\hline$<30$ & 7 & 14.0 \\
\hline $30-$ & 31 & 62.0 \\
\hline $40-55$ & 12 & 24.0 \\
\hline \multicolumn{3}{|l|}{ Marital status } \\
\hline Single & 8 & 16.0 \\
\hline Married & 39 & 78.0 \\
\hline Widowed & 2 & 4.0 \\
\hline Divorced & 1 & 2.0 \\
\hline \multicolumn{3}{|l|}{ Having children $(n=42)$} \\
\hline Yes & 37 & 88.1 \\
\hline No & 5 & 11.9 \\
\hline \multicolumn{3}{|l|}{ Qualification } \\
\hline Nursing diploma & 9 & 18.0 \\
\hline Nursing bachelor & 5 & 10.0 \\
\hline Public health bachelor & 11 & 22.0 \\
\hline $\begin{array}{l}\text { Medical technologists (lab, } \\
\text { radiologists) }\end{array}$ & 11 & 22.0 \\
\hline $\begin{array}{l}\text { Bachelor degree in other health } \\
\text { related field }\end{array}$ & 14 & 28.0 \\
\hline \multicolumn{3}{|c|}{ No. of schools in her responsibility } \\
\hline 1 & 48 & 96.0 \\
\hline 2 & 2 & 4.0 \\
\hline \multicolumn{3}{|c|}{ No. of students in her responsibility } \\
\hline $100-$ & 9 & 18.0 \\
\hline $200-$ & 33 & 66.0 \\
\hline $300-410$ & 8 & 16.0 \\
\hline \multicolumn{3}{|l|}{ Years of experience in schools } \\
\hline $1-$ & 21 & 42.0 \\
\hline 5- & 18 & 36.0 \\
\hline $10-$ & 9 & 18.0 \\
\hline $15-23$ & 2 & 4.0 \\
\hline \multicolumn{3}{|l|}{ Training courses in school health } \\
\hline None & 15 & 30.0 \\
\hline Once & 15 & 30.0 \\
\hline Twice & 20 & 40.0 \\
\hline
\end{tabular}

$40.0 \%$ of study sample received two training courses, while equal percentages of them either received one training course or did not received any training course at all $(30.0 \%)$ as presented in Table 1 .

All study samples performed most of activities related to prevention and control of communicable diseases. Isolation of students showing signs of a disease or sickness, informed parents to come school \& sent very sick student to home (100\%), while taken written consent from parents regarding the vaccination, prepare of vaccination room and giving relevant vaccinations and chemoprophylaxis according to diagnosis were the items of the lowest frequency of performance $(24.0 \%)$ as given in Table 2.

The younger age of studied sample the higher percentage of those adequately performed their activities regarding control and prevention of communicable disease $(71.4 \%$ among those in age group <30 years compared to $50.0 \%$ for those 40-50 years old). Also, $89.0 \%$ of the studied sample who had 100 to $<200$ students in their responsibilities performed this task adequately compared to only $37.5 \%$ who are responsible for 300-410 students. $80.0 \%$ of those who had nursing bachelor and $70.0 \%$ of those who got training courses twice performed their duties in this activity adequately. However, none of these findings had statistical significant difference $\mathrm{P}>0.05$ as shown in Table 3.

\section{DISCUSSION}

School health programs can play a unique and important role in the lives of children by helping improve their health-related knowledge, attitudes, and skills; healthy behaviours and health outcomes; education outcomes; and social outcomes. ${ }^{10}$ A high quality school health program is a coordinated and comprehensive set of courses, services, practices, and policies that meet the health and safety needs of students and school staff. ${ }^{11}$ The quality of the school health program operated within such standards of nursing care is dependent upon many factors. One of them is the proportion or ratio of the school nurse is very important, number of students in her responsibility. ${ }^{12,13}$

In the current study, the results reveals that the ratio of nurse to students was one nurse/200 to less than 300 students for about $66.0 \%$ of studied sample. This is less than the National Association of School Nurse in USA recommended. It recommended the ratio of nurse to students as 1:750. ${ }^{12,13}$ The importance of providing health services to students at school is widely recognized. According to the American Academy of paediatrics (AAP), at a minimum, schools should provide the following services: health screenings, verification of immunization status, and infectious disease reporting, assessment of minor health complaints, medication administration, and care for students with special health 
care needs; and capability to handle emergencies and other urgent situations. ${ }^{1}$

School nurse plays an important role in controlling the spread of communicable disease. By enforcing the state communicable disease regulations, excluding children who are ill, and promptly reporting all suspected cases of communicable disease, personnel working with children can help ensure the good health of the children in their care. ${ }^{15}$ Results of the present study revealed that $58.0 \%$ of the studied sample adequately performed their activities concerning communicable diseases. These results are in harmony with a study conducted to evaluate the school health services in Nomadic primary school in south- western Nigeria (2012) where $64.4 \%$ of school nurse had experienced control of communicable diseases. ${ }^{16}$ Occasionally a head checked for lice would be positive. When one child in a classroom was found to have head lice, it was the nurse's responsibility to check all of the children in the classroom for nits and lice. ${ }^{17}$ Results of the present study revealed that majority of the studied sample checked the students for pediculosis and signs of communicable diseases with equal frequency of (94.0\%). These results are in contrast with a survey conducted to assess school health services provided to Connecticut school district in U.S.A that reported low percentage of performance. $^{18}$

Table 2: Distribution of the studied sample of SHNs/SHSs working in primary schools by their practices in prevention and control of communicable diseases.

\begin{tabular}{|c|c|c|c|c|}
\hline \multirow{2}{*}{ Items } & \multicolumn{2}{|c|}{ Performed } & \multicolumn{2}{|c|}{ Not performed } \\
\hline & No. & $\%$ & No. & $\%$ \\
\hline \multicolumn{5}{|l|}{ The students are checked during class visits for: } \\
\hline -Pediculosis. & 3 & 6.0 & 47 & 94.0 \\
\hline -Scabies. & 7 & 14.0 & 43 & 86.0 \\
\hline -Tinea Capities. & 8 & 16.0 & 42 & 84.0 \\
\hline $\begin{array}{l}\text {-Signs of communicable diseases such as cheeks redness, tearing or red eyes, } \\
\text { running nose, skin eruptions, continuous cough or sneezing, or pallor. }\end{array}$ & 3 & 6.0 & 47 & 94.0 \\
\hline \multicolumn{5}{|l|}{ Early detection and management of communicable diseases: } \\
\hline $\begin{array}{l}\text {-The student suspected of being infected with communicable disease being } \\
\text { isolated from other classmates in class and sent to The school health doctor for } \\
\text { examination. }\end{array}$ & 5 & 10.0 & 45 & 90.0 \\
\hline -Associated symptoms of the disease being managed. & 14 & 28.0 & 36 & 72.0 \\
\hline -The parents are informed to attend. & 0 & 0.0 & 50 & 100.0 \\
\hline -The very sick students are sent home. & 0 & 0.0 & 50 & 100.0 \\
\hline -Each case is being followed to assure receiving suitable care. & 6 & 12.0 & 44 & 88.0 \\
\hline \multicolumn{5}{|l|}{ Care of contacts: } \\
\hline $\begin{array}{l}\text {-The contacts of a student who was isolated for a communicable disease are } \\
\text { observed for the longest incubation period of the disease. }\end{array}$ & 16 & 32.0 & 34 & 68.0 \\
\hline $\begin{array}{l}\text { - The relevant vaccinations and chemoprophylaxis are given according to the } \\
\text { diagnosis. }\end{array}$ & 38 & 76.0 & 12 & 24.0 \\
\hline - The necessary health education and medications are provided. & 11 & 22.0 & 39 & 78.0 \\
\hline \multicolumn{5}{|l|}{ Back to school after an communicable disease: } \\
\hline $\begin{array}{l}\text { - The health/medical certificate given by the school doctor or the authorized } \\
\text { doctor is recorded on return to school. }\end{array}$ & 9 & 18.0 & 41 & 82.0 \\
\hline \multicolumn{5}{|l|}{ Role of the nurse regarding the absent students: } \\
\hline -The students' absence records are reviewed & 21 & 42.0 & 29 & 58.0 \\
\hline \multicolumn{5}{|l|}{ Vaccinations: The nurse performed the following before giving the vaccine } \\
\hline -Taking written consent from the parents regarding the vaccinations & 38 & 76.0 & 12 & 24.0 \\
\hline -Educating the students regarding the benefits of the vaccinations. & 32 & 64.0 & 18 & 36.0 \\
\hline $\begin{array}{l}\text {-Recording the students who refused to be vaccinated at school and stressing } \\
\text { on the parents to vaccinate their children. }\end{array}$ & 14 & 28.0 & 36 & 72.0 \\
\hline -Confirmation from the vaccination certificate in case of refusal. & 17 & 34.0 & 33 & 66.0 \\
\hline -Providing the parents with information about the vaccination schedule. & 34 & 68.0 & 16 & 32.0 \\
\hline -Preparing the vaccination room according to the needed arrangements. & 38 & 76.0 & 12 & 24.0 \\
\hline \multicolumn{5}{|l|}{-Preparing sufficient vaccine for the students' number after: } \\
\hline -Checking the vaccine efficiency. & 21 & 42.0 & 29 & 58.0 \\
\hline -Checking the expiry date. & 21 & 42.0 & 29 & 58.0 \\
\hline
\end{tabular}


Table 3: Distribution of the studied sample of the SHNs/SHSs working in primary schools according to their level of performance concerning communicable diseases and their socio demographic data, years of experience and training courses.

\begin{tabular}{|c|c|c|c|c|c|c|}
\hline \multirow{3}{*}{ Items } & \multicolumn{4}{|c|}{ Communicable diseases } & \multirow{3}{*}{$X^{2}$} & \multirow{3}{*}{$\mathbf{P}$} \\
\hline & \multicolumn{2}{|c|}{ Inadequate } & \multicolumn{2}{|c|}{ Adequate } & & \\
\hline & No. & $\%$ & No. & $\%$ & & \\
\hline \multicolumn{5}{|l|}{ Nurse age in years } & \multirow{4}{*}{0.83} & \multirow{4}{*}{0.659} \\
\hline - $<30$ & 2 & 28.6 & 5 & 71.4 & & \\
\hline - $30-$ & 13 & 41.9 & 18 & 58.1 & & \\
\hline - $\quad 40-55$ & 6 & 50.0 & 6 & 50.0 & & \\
\hline \multicolumn{5}{|l|}{ Marital status } & \multirow{4}{*}{0.83} & \multirow{4}{*}{$0.660^{\wedge}$} \\
\hline - $\quad$ Single & 3 & 37.5 & 5 & 62.5 & & \\
\hline - $\quad$ Married & 16 & 41.0 & 23 & 59.0 & & \\
\hline - Widowed & 2 & 66.7 & 1 & 33.3 & & \\
\hline \multicolumn{5}{|l|}{ Having children } & \multirow{3}{*}{ FET } & \multirow{3}{*}{0.312} \\
\hline - Yes & 17 & 43.6 & 22 & 56.4 & & \\
\hline - $\quad$ No & 1 & 20.0 & 4 & 80.0 & & \\
\hline \multicolumn{5}{|l|}{ Qualification } & \multirow{5}{*}{1.5} & \multirow{5}{*}{$0.676^{\wedge}$} \\
\hline - $\quad$ Nursing diploma & 4 & 44.4 & 5 & 55.6 & & \\
\hline Nursing bachelor & 1 & 20.0 & 4 & 80.0 & & \\
\hline - Public health bachelor & 4 & 36.4 & 7 & 63.6 & & \\
\hline - $\quad$ Other related degrees & 12 & 48.0 & 13 & 52.0 & & \\
\hline \multicolumn{5}{|l|}{ Students Load } & \multirow{4}{*}{5.1} & \multirow{4}{*}{0.079} \\
\hline - $100-$ & 1 & 11.1 & 8 & 88.9 & & \\
\hline - $\quad 200-$ & 15 & 45.5 & 18 & 54.5 & & \\
\hline - $\quad 300-410$ & 5 & 62.5 & 3 & 37.5 & & \\
\hline \multicolumn{5}{|l|}{ Years of experience } & \multirow{5}{*}{4.6} & \multirow{5}{*}{$0.208^{\wedge}$} \\
\hline - $1-$ & 10 & 47.6 & 11 & 52.4 & & \\
\hline - $5-$ & 5 & 27.8 & 13 & 72.2 & & \\
\hline - $10-$ & 4 & 44.4 & 5 & 55.6 & & \\
\hline - $\quad 15-23$ & 2 & 100.0 & 0 & 0.0 & & \\
\hline \multicolumn{5}{|l|}{ No. of training courses } & \multirow{4}{*}{2.1} & \multirow{4}{*}{0.349} \\
\hline - $\quad$ No & 8 & 53.3 & 7 & 46.7 & & \\
\hline - Once & 7 & 46.7 & 8 & 53.3 & & \\
\hline - Twice & 6 & 30.0 & 14 & 70.0 & & \\
\hline
\end{tabular}

FET: P value based on Fisher exact probability; ${ }^{\wedge}: \mathrm{P}$ value based on Mont Carlo exact probability.

Because of the child-expanding world, his participation in activities with other children and his exposure to environmental conditions unlike those of his home, he frequently comes in contact with organisms, which cause communicable diseases. ${ }^{19}$

In the present study concerning the role of nurses towards a child with communicable diseases, all the studied sample $(100.0 \%)$ performed isolation of students showing signs of a disease or sickness, informed parents to come school \&sent very sick student to home. These results are in contrast with a study performed in Alexandria (1995) as about $67 \%$ of study sample were performed isolation of students showing signs of a disease or sickness. ${ }^{20}$ The results of present study indicate that study sample had good practice regarding controlling the spread of communicable disease.
Vaccination to protect against disease is one of the great success stories in medicine. School nurse are an important line of defense against vaccine-preventable disease. ${ }^{21}$ The results of the present work revealed that nearly most of the studied sample performed their activities inadequately regarding vaccinations as only $24.0 \%$ of them taken written consent from parents regarding the vaccination. This may be due to that school vaccinations are obligatory and the opinion of parent is not required before conducting these vaccinations, and also only $24.0 \%$ of the studied samples prepare the vaccination room according to the needed arrangements. The reason of that may be because they did not have enough authority in this aspect. These findings are in contrast with that reported by Al Dahnaim et al in Qatar revealed that $95.0 \%$ of school nurses agreed that they monitoring immunization activities. ${ }^{22}$ 


\section{CONCLUSION}

School nurses are important members in the health team of the school. They provided services at school, with the families of the children and in the community. More than half of the studied sample performed their duties adequately performed their activities concerning communicable diseases. The study recommends increase awareness of school principals on the school-nursing role, especially in issues related to prevention and control of communicable diseases.

Funding: No funding sources

Conflict of interest: None declared

Ethical approval: The study was approved by the Institutional Ethics Committee

\section{REFERENCES}

1. Nader PR. The concept of comprehensiveness in the design and implementation of school health programs. Journal of School Health. 1990;60:133-7.

2. Kickbush I. Health promotion into the 21 st century. Learning for Health. 1996;8:3-5.

3. The National Council for Childhood and Motherhood. Initial report on the implementation of the convention on the rights of child. Arab Republic of Egypt. 1992.

4. WHO. Report on the first regional conference on health promoting schools in the Eastern Mediterranean Region. Damascus, Syrian Arab Republic. 2007.

5. Stanhope M, Lancaster J. Community health nursing: process and practice for promoting health. 2nd edition. Washington: Mosby company; 1988: 443-788.

6. Miller F. Dimension of community health. USA: Wim Company; 1984: 242.

7. American Academy of Pediatrics. Red Book: Report of the Committee on Infectious Diseases. 25th edition. Elk Grove Village, IL: American Academy of Pediatrics; 2003.

8. Maryland State School Health Services Guidelines. Management of Communicable Diseases in a School Setting, 2016. Available: http://www.mary landpublicschools.org/NR/rdonly. Accessed on 22 February 2016.

9. Ewert D, Deckert AW. School communicable disease management guidelines, 2011. Available from: http://www.co.shasta.ca.us/HHSA/healthand safety. Accessed on 22 February 2016.
10. Kolb LJ. Education reform and the goals of the modern school health program. State education standard. 2002;3:4-11.

11. Kann L, Brener N, Wechler H. Overview and summary: School health policies and programs study. J Sch Health. 2007;77:385-97.

12. National Association of School Nurses. Definition of school nursing. 1999. Available at URL: http://www.nasn.org. Accessed on 05 April 2016.

13. Smith GM, Maurer FA. Community health nursing: theory and practices. 2nd edition. Volume 38. London: W.B. Saunders Company; 1995: 811-814.

14. American Academy of Pediatrics (AAP). The role of the school nurse in providing school health services. J SchNurs. 2003;19:127-9.

15. Centers for Disease Control and Prevention. The ABCs of safe and healthy child care: The handbook for child care providers, department of health and human services, U.S. Public health service, centers for disease control and prevention, 1996.

16. Ibhafidon A, Ejifugha AU. Evaluation of school health services in Nomadic primary schools in southwestern Nigeria. Mediterranean Journal of Social Sciences. 2012;3:155-64.

17. Rademacher PA. The nurse in the school health office: Exploring health care in a public school. Nebraska: College of education and human sciences, University of Nebraska. 2012: 139.

18. Stewart MN. Health services program information survey. Final report. The Connecticut state department of education. 2004.

19. White JM, Leon S, Begg NT. "Cover": Cover of vaccination evaluated rapidly. Communicable diseases report. 1994;4:18-9.

20. Mohamed SB. A study of the role of the nurse in the school health program in Alexandria. Thesis, MPHsc. Alexandria: High institute of public health, Alexandria University. 1995: 30-47.

21. Greene A. Vaccination fears: What the school nurse can do. J Sch Nurs. 2002;18:31-5.

22. Al-Dahnaim L, Said H, Salama R, Bella H, Malo D. Perceptions of school nurses and principals towards nurse role in providing school health services in Qatar. Journal of the Egyptian public health. 2013;88:19-25.

Cite this article as: Arhaim SM, Elzahaf RA. Assessment of the role of school health nurses/school health supervisors in the prevention and control of communicable diseases in primary schools in Derna, Libya. Int J Community Med Public Health 2016;3:2775-80. 